\title{
AN INTERPOLATION FORMULA IN RELATION TO A POLYNOMIAL INEQUALITY OF SCHUR
}

\author{
RICHARD FOURNIER
}

Abstract. We study a recent interpolation formula for algebraic polynomials due to Dryanov, Fournier and Ruscheweyh and its links to a polynomial inequality of Schur.

Mathematics subject classification (2010): 30C10, 41A17, 42A05.

Keywords and phrases: Polynomials, inequalities of Bernstein, Markov and Schur, interpolation formula.

\section{REFERENCES}

[1] P. Borwein, T. Erdélyi, Polynomials and polynomial inequalities, Springer-Verlag, New-York, 1995.

[2] D. Dryanov, R. Fournier, A note on Bernstein and Markov type inequalities, J. Approx. Theory 136(2005), 84-90.

[3] D. Dryanov, R. Fournier, St. Ruscheweyh, Some extensions of the Berstein inequalities for polynomials, Rocky Mountain J. Math 37 (2007), 1155-1165.

[4] D. Dryanov, R. Fournier, Equality cases for two polynomial inequalities, Annuaire Univ. Sofia Fac. Math. Inform 99(2009), 169-181.

[5] R. J. DUFFIN, A. C. SCHAEFFER, A refinement of an inequality of the brothers Markoff, Trans. Amer. Math. Soc., 50(1941), 517-528.

[6] R. Fournier, S. Ruscheweyh, L. C. Salinas, On a discrete norm for polynomials, J. Math. Anal. Appl. 396(2012), 425-433.

[7] R. Fournier, S. Ruscheweyh, On two interpolation formulas for complex polynomials, Fields Inst. Commun. 81(2018), 225-234.

[8] R. Fournier, S. Ruscheweyh, On two interpolation formulas for polynomials in the unit disc, Springer Optim. Appl., 117(2017), 75-82.

[9] C. Frappier, Q. I. Rhaman, St. Ruscheweyh, New inequalities for polynomials, Trans. Amer. Math. Soc. 288(1985), 69-99.

[10] P. Nevai, The AnONymous Referee, The Berstein inequality and the Schur inequality are equivalent, J. Approx. Theory 182(2014), 103-109.

[11] Q. I. Rahman, G. SchmeIsser, Analytic theory of polynomials, Oxford University Press, Oxford, 2002.

[12] St. Ruscheweyh, Convolutions in geometric function theory, Les Pressses de l'Université de Montréal, Montréal, 1982.

[13] A. SHADRIN, Twelve proofs of the Markov inequality, in Approximation theory: a volume dedicated to Borislav Bojanov, Drinov Acad. Publ. House, Sofia, 2004.

[14] T. Sheil-S Mall, Complex Polynomials, Cambridge University Press, Cambridge, 2002. 